\title{
Thermal Vacuum/Balance Test Results of Swift BAT with Loop Heat Pipe Thermal System
}

\author{
Michael K. Choi* \\ NASA Goddard Space Flight Center, Greenbelt, MD 20771
}

\begin{abstract}
The Swift Burst Alert Telescope (BAT) Detector Array is thermally well coupled to eight constant conductance heat pipes (CCHPs) embedded in the Detector Array Plate (DAP), and two loop heat pipes (LHPs) transport heat from the CCHPs to a radiator. The CCHPs have ammonia as the working fluid and the LHPs have propylene as the working fluid. Precision heater controllers, which have adjustable set points in flight, are used to control the LHP compensation chamber and Detector Array XA1 ASIC temperatures. The radiator has AZTek's AZW-LA-II low solar absorptance white paint as the thermal coating, and is located on the anti-sun side of the spacecraft. A thermal balance (T/B) test on the BAT was successfully completed. It validated that the thermal design satisfies the temperature requirements of the BAT in the flight thermal environments. Instrument level and observatory level thermal vacuum (T/V) cycling tests of the BAT Detector Array by using the LHP thermal system were successfully completed. This paper presents the results of the $T / B$ test and $T / V$ cycling tests.
\end{abstract}

$\begin{array}{ll}B A T & =\text { Burst Alert Telescope } \\ B C D H & =\text { Block Communication and Data Handling } \\ B V R & =\text { Block Voltage Regulator } \\ C C & =\text { compensation chamber } \\ C C H P & =\text { constant conductance heat pipe } \\ C Z T & =\text { cadmium zinc telluride } \\ D A P & =\text { Detector Array Plate } \\ D M & =\text { Detector Module } \\ G S F C & =\text { Goddard Space Flight Center } \\ L H P & =\text { loop heat pipe } \\ M L I & =\text { multi-layer insulation } \\ T / B & =\text { thermal balance } \\ T / V & =\text { thermal vacuum } \\ V C H P & =\text { variable conductance heat pipe } \\ V D A & =\text { vacuum deposited aluminum }\end{array}$

\section{Introduction}

THE BAT is the primary instrument on the Swift spacecraft. The Swift mission is part of the National Aeronautics and Space Administration (NASA) Medium-Size Explorer (MIDEX) Program, and is managed by Goddard Space Flight Center (GSFC). It is designed to detect gamma ray burst over a broad region of the sky in a low Earth orbit of $600-\mathrm{km}$ altitude and quickly align the telescopes on the spacecraft to the gamma ray source. It is scheduled to launch in October 2004. The Swift mission is a first of its kind of multi-wavelength transient observatory for gamma ray burst astronomy. Its mission life is 2 years. The inclination is $22^{\circ}$ maximum. The spacecraft bus voltage to the instruments is in the $24 \mathrm{~V}$ to $35 \mathrm{~V}$ range. The instruments will be turned off when the voltage is below 27 V. Figure 1 shows the location of the BAT on the Swift observatory. The BAT is mounted to the optical bench through five titanium flexures.

* Swift Thermal Systems Lead Engineer, Thermal Engineering Branch/Code 545, AIAA Associate Fellow. 
The BAT has been developed at GSFC. Its telescope assembly consists of 256 Detector Modules (DMs) in the Detector Array. There are 16 Detector Array Blocks. Each Block holds 16 DMs, 3 Block Voltage Regulator (BVR) units and 3 Block Command \& Data Handling (BCDH) units. The power dissipation of each Block has been measured to be $13 \mathrm{~W}$. Therefore the total power dissipation of the 16 Blocks is $208 \mathrm{~W}$. The DAP is $1.3 \mathrm{~m}(4.3 \mathrm{ft}) \mathrm{x} 1$ $\mathrm{m}(3.3 \mathrm{ft})$, accommodates all the 16 Blocks. It also provides the mounting surface and the positional stability for the Blocks. The DMs are located at the top ( $+\mathrm{X}$ side) of the DAP and is enclosed by graded- $\mathrm{Z}$ shields on the sides and a coded mask at the top. The BVRs and BCDHs are located at the bottom ( $\mathrm{X}$ side) of the DAP. Eight Blocks are located at the front $(-Z$ side or radiator side) of the DAP, and eight are located at the rear ( $-Z$ side $)$ of the DAP. The DMs and top of DAP are insulated with a 7-layer multi-layer insulation (MLI). There is a $5.08 \mathrm{~cm}(2 \mathrm{in}) \times 5.08 \mathrm{~cm}$ ( 2 in) MLI cutout over each Block heater controller so that heat radiates from the heater controller to the mask. The exterior of the mask, graded-Z shields and bottom of DAP is insulated with a 15-layer MLI. Figure 2 shows the BAT telescope assembly. Figure 3 shows the 16 Blocks after they were integrated to the telescope assembly, and before the LHPs and radiator were integrated.

The BAT Detector Array is thermally well coupled to eight CCHPs embedded in the DAP, and two loop heat pipes (LHPs) transport heat from the CCHPs to a radiator. The CCHPs have ammonia as the working fluid and the LHPs have propylene as the working fluid. Precision heater controllers, which have adjustable set points in flight, are used to control the LHP compensation chamber and Detector Array XA1 ASIC temperatures. ${ }^{1}$ The radiator has AZ-Tek's AZW-LA-II low solar absorptance white paint as the thermal coating. Figure 4 illustrates the LHP thermal system. The LHP thermal system characteristics and ground/flight operation procedure were presented by Choi. ${ }^{2}$

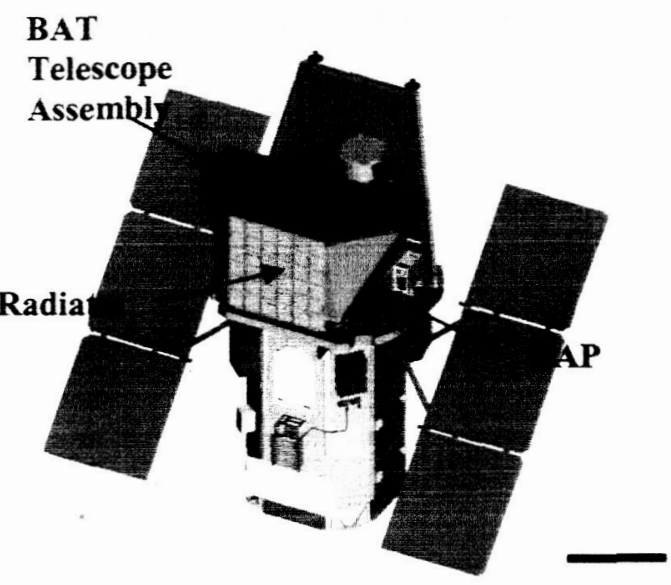

Figure 1. BAT on Swift Observatory.

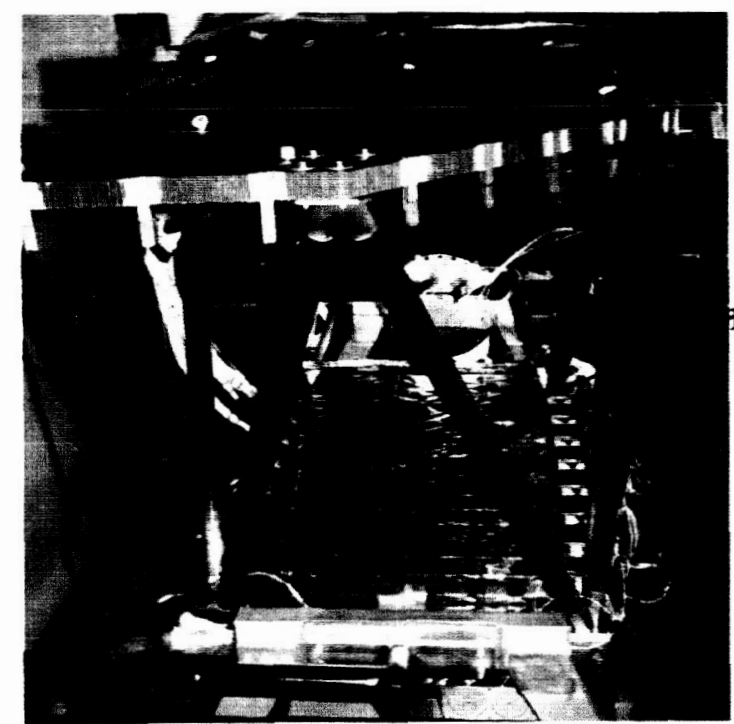

Figure 3. Blocks Integrated to BAT Telescope.

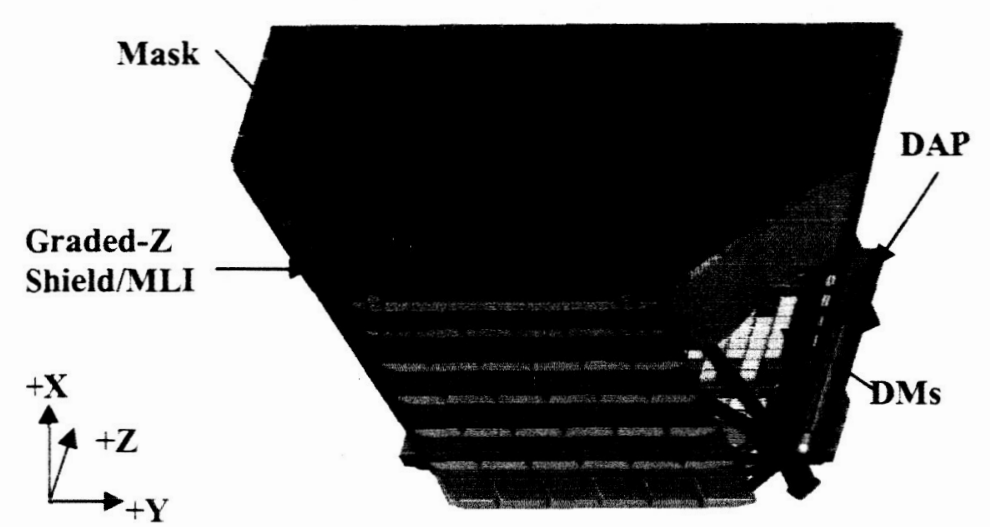

Figure 2. BAT Telescope Assembly.

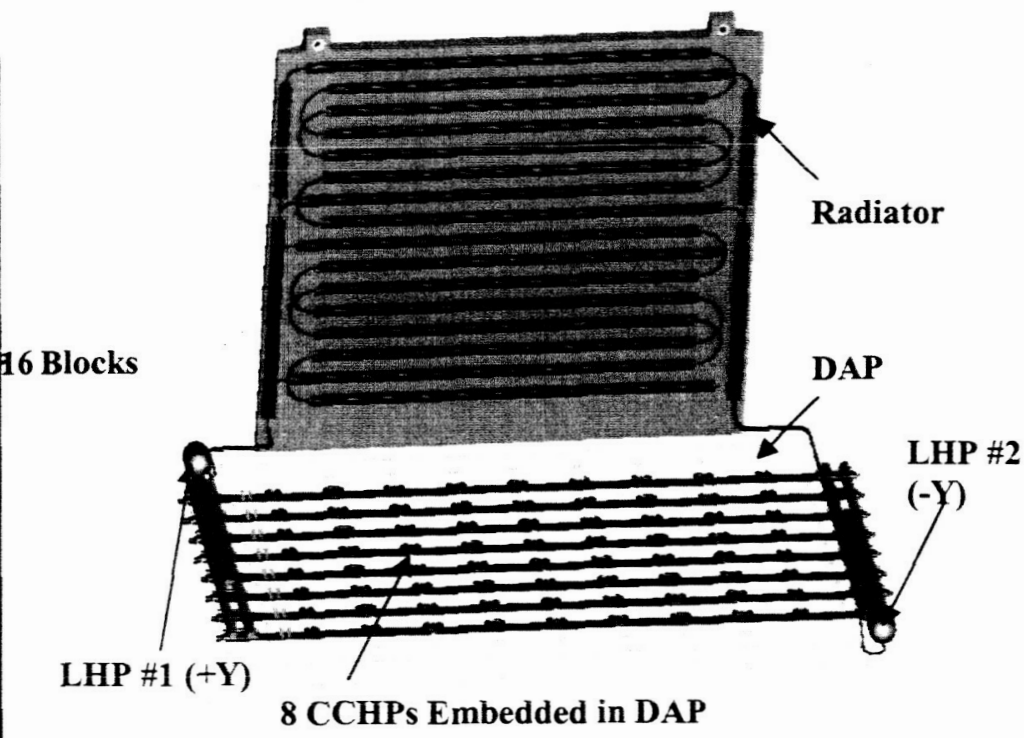

Figure 4. BAT LHP Thermal System Schematic.

2

American Institute of Aeronautics and Astronautics 
A T/B test was performed on the BAT telescope assembly at the instrument level in June 2003. A T/V cycling test was performed on the BAT at the instrument level in October/November 2003. During the Swift observatory level $\mathrm{T} / \mathrm{V}$ test in May/June 2004 , T/V cycling was also performed on the BAT to add 4 cycles to satisfy a total of 12 cycles before launch. The observatory consists of the spacecraft bus and instrument module. Figure 5 shows the BAT flight hardware on the observatory.

The T/B test objectives were: (1) to validate the instrument thermal model; and (2) to assure that the instrument thermal design satisfies the temperature requirements of the instrument in the flight thermal environments.

The $T / V$ cycling test objective was to verify the acceptability of the BAT by (1) performing qualification level $\mathrm{T} / \mathrm{V}$ cycling on instrument; (2) demonstrating satisfactory operation of instrument in functional modes at temperatures in excess of extremes predicted for the mission and during temperature transitions; and (3) demonstrating that permanent degradation will not result from exposure to survival mode temperatures when instrument is tested in a nonoperational mode at cold survival exposure temperatures.

This paper presents the results of the T/B test of the BAT telescope assembly and T/V cycling tests of the BAT Detector Array Blocks.

\section{Thermal Balance Test}

The T/B test items included the flight telescope assembly. The titanium flexures of the telescope assembly were clamped to a $1.219 \mathrm{~m}(4 \mathrm{ft}) \times 1.524 \mathrm{~m}(5 \mathrm{ft})$ cold plate in Chamber 238 at GSFC. The cold plate also simulated the optical bench thermally. It was thermally isolated from the chamber floor by G-10 Blocks. Because of CCHPs on the top of the DAP and embedded in the DAP, the DAP needed to be maintained horizontal, with end-to-end tilts not to exceed $0.1 \mathrm{inch}$. An inclinometer was used to measure the tilt angles prior to closing the chamber door and pumpdown. The tilt angles of the cold plate were measured to be $0.14^{\circ}$ in both horizontal axes. The tilt of the radiator in the $\mathrm{Y}$-axis was measured to be $0.08^{\circ}$, and that of the zeolite filter box in the $\mathrm{Z}$-axis was $0.24^{\circ}$.

The chamber shroud simulated the heat sink for the loop heat pipes. A $1.219 \mathrm{~m}(4 \mathrm{ft}) \times 1.524 \mathrm{~m}(5 \mathrm{ft})$ cryopanel in front of the radiator simulated the heat sink for the radiator. A $2.438 \mathrm{~m}(8 \mathrm{ft}) \times 2.438 \mathrm{~m}(8 \mathrm{ft})$ cryopanel, $1.168 \mathrm{~m}$ $(3.83 \mathrm{ft})$ above the mask, simulated the heat sink for the mask MLI. Five heater plates simulated the thermal environment of the 5 fringe graded-Z shield sides of the telescope assembly covered by MLI and a contamination bag. Table 1 presents the sink temperatures in the T/B test.

\section{A. Instrumentation}

Thermocouples were used to monitor the temperatures of the BAT telescope assembly, cryopanels, cold plate and heater plates. There were 232 thermocouples utilized in the BAT T/B test - 167 for the telescope assembly, 20 for the cryopanels and cold plate ( 4 each), and 20 for the heater plates ( 4 each). Because better temperature accuracy was needed to verify the operating mode heater controller performance for the LHP compensation chambers, YSI thermistors were used. There were 2 thermistors for each LHP - one on the compensation chamber, and one on the liquid line outlet of the heat exchanger.

\section{B. Test Results}

Figure 6 presents the temperature profile of the BAT Blocks achieved in the T/B test, which included the LHP controllability test. Temperatures of the test thermistors adjacent to the flight thermistors for the LHP compensation chamber heater controllers are shown in Fig. 7. From these figures, the relationship between the Block temperature and the compensation chamber was determined. 
Table 2 summarizes the temperatures of the LHPs, BAT Blocks and mask when thermal stabilization was declared for the hot operating T/B test. The temperature of the test thermistor close to the flight thermistor of the LHP compensation chamber heater controller was $7.2^{\circ} \mathrm{C}$ for LHP \#1. It was $7.24^{\circ} \mathrm{C}$ for LHP \#2. They were very close to the $7^{\circ} \mathrm{C}$ set point, which determines the LHP evaporator and BAT DM temperatures. The temperature of the vapor line was $6.96^{\circ} \mathrm{C}$ for LHP \#1 and $8.01^{\circ} \mathrm{C}$ for LHP \#2. The radiator had a large temperature gradient. The temperature was $-0.45^{\circ} \mathrm{C}$ at the center and $-28.66^{\circ} \mathrm{C}$ at the lower right $(+\mathrm{Y} /-\mathrm{X})$ comer. The temperature of lower condenser pass $2 \mathrm{a}$ was $-23.28^{\circ} \mathrm{C}$ for LHP \#1 and $-25.37^{\circ} \mathrm{C}$ for LHP \#2. The temperatures of the DMs were $14.65^{\circ} \mathrm{C}$ minimum and $16.51^{\circ} \mathrm{C}$ maximum. Therefore the temperature gradient was $1.86^{\circ} \mathrm{C}$, and met the $\pm 1^{\circ} \mathrm{C}$ gradient requirement. The average temperature of the DMs was $15.74^{\circ} \mathrm{C}$. It was $8.74^{\circ} \mathrm{C}$ warmer than the $7^{\circ} \mathrm{C}$ set point of the LHP compensation chamber heater controllers.

Table 3 summarizes the temperatures of the LHPs, BAT Blocks and mask when thermal stabilization was declared for the cold operating T/B test. The temperature of the test thermistor close to the flight thermistor of the LHP compensation chamber heater controller was $-4.58^{\circ} \mathrm{C}$ for LHP \#1. It was $-4.65^{\circ} \mathrm{C}$ for LHP \#2. They were close to the $-5^{\circ} \mathrm{C}$ set point. The temperature of the vapor line was $4.35^{\circ} \mathrm{C}$ for LHP $\# 1$ and $-4.15^{\circ} \mathrm{C}$ for LHP $\# 2$. The temperature gradient of the radiator was also large $\left(-12.38^{\circ} \mathrm{C}\right.$ at the center and $-39.56^{\circ} \mathrm{C}$ at the lower right corner). The radiator temperature was about $10^{\circ} \mathrm{C}$ colder than that of the hot operating $\mathrm{T} / \mathrm{B}$ test, because the radiator cryopanel temperature was $10^{\circ} \mathrm{C}$ colder. The temperature of lower condenser pass $2 \mathrm{a}$ was $-33.59^{\circ} \mathrm{C}$ for LHP $\# 1$ and $-35.65^{\circ} \mathrm{C}$ for LHP \#2. The temperatures of the DMs were $2.21^{\circ} \mathrm{C}$ minimum and $4.1^{\circ} \mathrm{C}$ maximum. Therefore the temperature gradient was $1.89^{\circ} \mathrm{C}$, and met the $\pm 1^{\circ} \mathrm{C}$ gradient requirement. The average temperature of the DMs was $3.27^{\circ} \mathrm{C}$. It was $8.27^{\circ} \mathrm{C}$ warmer than the $-5^{\circ} \mathrm{C}$ set point of the LHP compensation chamber heater controllers.

From the results of the hot operating T/B test and cold operating T/B test, when the BAT Detector Array is powered on and both LHPs are running, the average temperature of the DMs is about $8.5^{\circ} \mathrm{C}$ warmer than the set point of the LHP compensation chamber heater controllers. It is close to the $10^{\circ} \mathrm{C}$ gradient predicted in designing the LHP thermal system.

Table 4 summarizes the temperatures of the LHPs, BAT Blocks and mask when thermal stabilization was declared for the cold survival T/B re-test, which was included in the BAT instrument T/V cycling test. The voltage for the survival heaters was $24 \mathrm{~V}$. The temperature of the test thermistor close to the flight thermistor of the LHP compensation chamber heater controller was $-12.91^{\circ} \mathrm{C}$ for LHP \#1. It was $-12.26^{\circ} \mathrm{C}$ for LHP $\# 2$. They were within the redundant survival heater thermostat set point of $-13^{\circ} \mathrm{C}$ closed $/-8^{\circ} \mathrm{C}$ open. The temperature of the evaporator was $-21.65^{\circ} \mathrm{C}$ for LHP $\# 1$ and $-21.05^{\circ} \mathrm{C}$ for LHP \#2. The evaporator temperatures were colder than the compensation chambers, such that the LHPs shut down. Because there was no heat transport by the LHPs to the radiator, the temperature gradient of the radiator was negligible $\left(-91.78^{\circ} \mathrm{C}\right.$ at the center and $-93.09^{\circ} \mathrm{C}$ at the lower right corner). The temperature of lower condenser pass $2 \mathrm{a}$ was $-93.44^{\circ} \mathrm{C}$ for $\mathrm{LHP} \# 1$ and $-91.73^{\circ} \mathrm{C}$ for $\mathrm{LHP} \# 2$. The temperatures of the DMs were $-20.89^{\circ} \mathrm{C}$ minimum and $-18.76^{\circ} \mathrm{C}$ maximum. They met the $-21^{\circ} \mathrm{C}$ cold survival limit requirement. Note that only the redundant survival heaters were enabled. It simulated a multiple failure case in flight, with the primary survival heaters disabled and the spacecraft bus voltage at the minimum $(24 \mathrm{~V})$ all the time. Additionally the voltage was at the power supply for the survival heaters. Due to line losses for the ground support equipment (GSE) harness, the voltage at the survival heaters was less $24 \mathrm{~V}$. Nominally in flight when both the primary and redundant survival heaters are enabled, and without the GSE harness, the temperatures of the DMs and DAP will be significantly warmer.

The T/B test was the first time that the BAT had the LHPs and radiator integrated to it and tested in vacuum. It showed that the two LHPs worked in harmony thermally to share the heat transport from the DAP to the radiator.

Table 1. Sink Temperatures in T/B Test.

\begin{tabular}{|c|c|c|c|}
\hline Facility & Hot Op & Cold Op & $\begin{array}{c}\text { Cold } \\
\text { Survival }\end{array}$ \\
\hline Chamber Shroud & -43 & -85 & -85 \\
\hline Cryopanel: Radiator & -97 & -117 & -117 \\
\hline Cryopanel: Mask & -55 & -89 & -89 \\
\hline $\begin{array}{c}\text { Cold Plate (Optical } \\
\text { Bench Simulator) }\end{array}$ & 10 & -20 & -20 \\
\hline Heater Panel \#1 & -22 & -67 & -67 \\
\hline Heater Panel \#2 & -49 & -82 & -82 \\
\hline Heater Panel \#3 & -49 & -82 & -82 \\
\hline Heater Panel \#4 & -37 & -87 & -87 \\
\hline Heater Panel \#5 & -37 & -87 & -87 \\
\hline
\end{tabular}

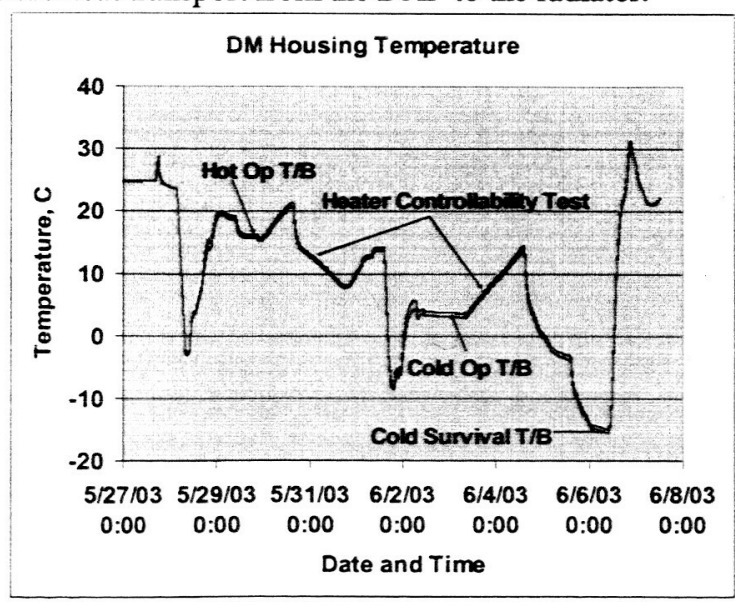

Figure 6. Block DM Temperatures in Instrument Level T/B Test.

4

American Institute of Aeronautics and Astronautics 


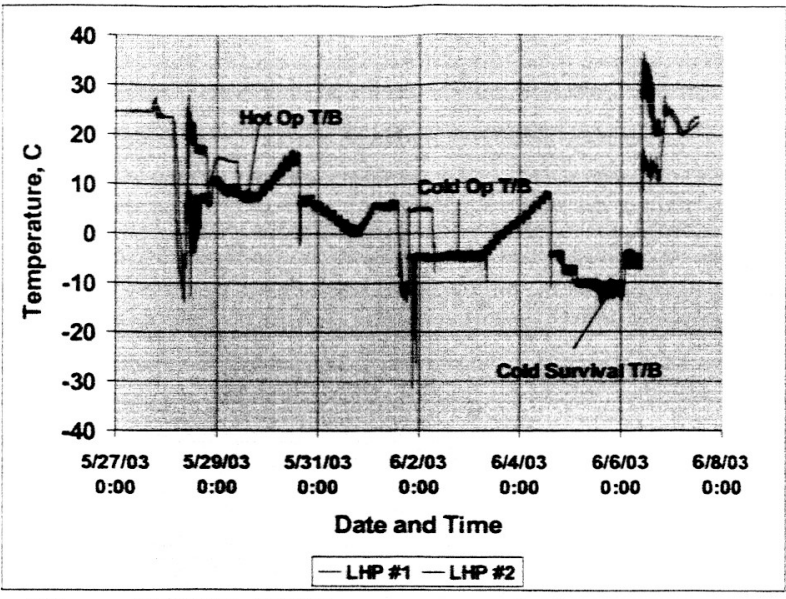

Figure 7. LHP CC Temperatures in Instrument Level T/B Test.

Figure 8 presents the temperatures of the BAT DMs in the observatory level cold survival T/B test. With only the redundant survival heaters enabled and a spacecraft voltage of $32 \mathrm{~V}$, the temperatures of the DMs when thermal stabilization was declared were in the $-10.35^{\circ} \mathrm{C}$ to $-11.01^{\circ} \mathrm{C}$ range. The nominal voltage in flight is $32 \mathrm{~V}$.

The $T / B$ test results have validated that the thermal design satisfies the thermal requirements of the instrument in the flight thermal environments.

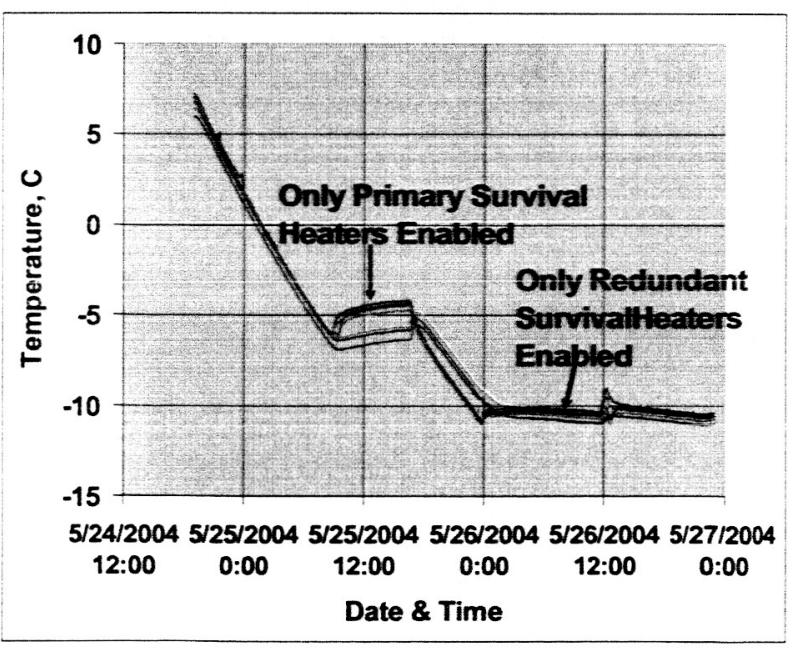

Figure 8. Block DM Temperatures in Observatory Level Cold Survival T/B Test.
Table 2. Hot Operating T/B Test Results $\left({ }^{\circ} \mathrm{C}\right)$.

\begin{tabular}{|c|c|}
\hline LHP $1(+Y)$ CC thermistor & $\overline{7.2}$ \\
\hline LHP 1 evaporator & 7.38 \\
\hline LHP 1 vapor line & 6.96 \\
\hline LHP 1 vapor line at condenser & 4.97 \\
\hline LHP 1 lower condenser pass 2 a & -23.28 \\
\hline LHP 1 upper condenser pass 3 a & -8.71 \\
\hline LHP 1 liquid line outlet of condenser & -15.38 \\
\hline LHP 1 liquid inlet to heat exchanger & -11.31 \\
\hline LHP 1 liquid line outlet of heat exchanger & -2.79 \\
\hline LHP 1 liquid return at CC & -3.1 \\
\hline LHP $2(-Y)$ CC thermistor & 7.24 \\
\hline LHP 2 evaporator & 8.78 \\
\hline LHP 2 vapor line & 8.01 \\
\hline LHP 2 vapor line at condenser & 4.26 \\
\hline LHP 2 lower condenser pass 2 a & -25.37 \\
\hline LHP 2 upper condenser pass 3 a & -3.56 \\
\hline LHP 2 liquid line outlet of condenser & -15.22 \\
\hline LHP 2 inlet to heat exchanger & -13.93 \\
\hline LHP 2 liquid line outlet of heat exchanger & -1.65 \\
\hline LHP 2 liquid return at CC & 0.14 \\
\hline Radiator Backside, Center & -0.45 \\
\hline Radiator Backside, $+\mathrm{Y} / \mathrm{X}$ Corner & -28.66 \\
\hline DM 1 Housing, $-Z$ & 14.8 \\
\hline DM 2 Housing, $-Z$ & 15.26 \\
\hline DM 3 Housing, $-Z$ & 15.77 \\
\hline DM 4 Housing, $-Z$ & 16.13 \\
\hline DM 5 Housing, $-Z$ & 15.78 \\
\hline DM 6 Housing, $-Z$ & 15.55 \\
\hline DM 7 Housing, - Z & 15.65 \\
\hline DM 8 Housing, $-Z$ & 14.65 \\
\hline DM 9 Housing, $+Z$ & 15.9 \\
\hline DM 10 Housing, $+\mathrm{Z}$ & 16.46 \\
\hline DM 11 Housing, $+Z$ & 16.51 \\
\hline DM 12 Housing, $+Z$ & 16.2 \\
\hline DM 13 Housing, $+Z$ & 16.29 \\
\hline DM 14 Housing, $+Z$ & 16.29 \\
\hline DM 15 Housing, $+Z$ & 15.69 \\
\hline DM 16 Housing, $+\mathrm{Z}$ & 14.97 \\
\hline DAP Top Facesheet, -Y & 13.63 \\
\hline DAP Top Facesheet, $+Y$ & 13.65 \\
\hline DAP Bottom Facesheet, - Y & 13.7 \\
\hline Mask & 5.6 \\
\hline
\end{tabular}

5

American Institute of Aeronautics and Astronautics 
Table 2. Cold Operating T/B Test Results $\left({ }^{\circ} \mathrm{C}\right)$.

\begin{tabular}{|c|c|}
\hline LHP $1(+Y)$ CC thermistor & -4.58 \\
\hline LHP 1 evaporator & -3.81 \\
\hline LHP 1 vapor line & -4.35 \\
\hline LHP 1 vapor line at condenser & -7.58 \\
\hline LHP 1 lower condenser pass 2 a & -33.59 \\
\hline LHP 1 upper condenser pass 3 a & -20.45 \\
\hline LHP 1 liquid line outlet of condenser & -26.42 \\
\hline LHP 1 liquid inlet to heat exchanger & -19.74 \\
\hline LHP 1 liquid line outlet of heat exchanger & -11.83 \\
\hline LHP 1 liquid return at $\mathrm{CC}$ & 2.04 \\
\hline LHP $2(-Y)$ CC thermistor & -4.65 \\
\hline LHP 2 evaporator & -3.45 \\
\hline LHP 2 vapor line & -4.15 \\
\hline LHP 2 vapor line at condenser & -6.15 \\
\hline LHP 2 lower condenser pass 2 a & -35.65 \\
\hline LHP 2 upper condenser pass 3 a & -14.48 \\
\hline LHP 2 liquid line outlet of condenser & -26.43 \\
\hline LHP 2 inlet to heat exchanger & -23.94 \\
\hline LHP 2 liquid line outlet of heat exchanger & -16.34 \\
\hline LHP 2 liquid return at CC & -11.64 \\
\hline Radiator Backside, Center & -12.38 \\
\hline Radiator Backside, $+\mathrm{Y} / \mathrm{X}$ Corner & -39.56 \\
\hline DM 1 Housing, $-Z$ & 2.29 \\
\hline DM 2 Housing, $-Z$ & 2.63 \\
\hline DM 3 Housing, $-Z$ & 3.2 \\
\hline DM 4 Housing, $-Z$ & 3.61 \\
\hline DM 5 Housing, $-Z$ & 3.20 \\
\hline DM 6 Housing, $-Z$ & 3.11 \\
\hline DM 7 Housing, $-Z$ & 3.30 \\
\hline DM 8 Housing, $-Z$ & 2.21 \\
\hline DM 9 Housing, $+Z$ & 3.62 \\
\hline DM 10 Housing, $+Z$ & 4.08 \\
\hline DM 11 Housing, $+Z$ & 4.10 \\
\hline DM 12 Housing, $+Z$ & 3.66 \\
\hline DM 13 Housing, $+Z$ & 3.81 \\
\hline DM 14 Housing, $+Z$ & 3.83 \\
\hline DM 15 Housing, $+Z$ & 3.15 \\
\hline DM 16 Housing, $+Z$ & 2.52 \\
\hline DAP Top Facesheet, -Y & 1.92 \\
\hline DAP Top Facesheet, $+Y$ & 1.86 \\
\hline DAP Bottom Facesheet, - Y & 1.47 \\
\hline Mask & -5.1 \\
\hline
\end{tabular}

Table 3. Cold Survival T/B Test Results $\left({ }^{\circ} \mathrm{C}\right)$.

\begin{tabular}{|c|c|}
\hline LHP $1(+Y)$ CC thermistor & -12.91 \\
\hline LHP 1 evaporator & -21.65 \\
\hline LHP 1 vapor line & -24.0 \\
\hline LHP 1 vapor line at condenser & -52.76 \\
\hline LHP 1 lower condenser pass 2 a & -93.44 \\
\hline LHP 1 upper condenser pass 3 a & -94.2 \\
\hline LHP 1 liquid line outlet of condenser & -92.9 \\
\hline LHP 1 liquid inlet to heat exchanger & -58.99 \\
\hline LHP 1 liquid line outlet of heat exchanger & -24.02 \\
\hline LHP 1 liquid return at $\mathrm{CC}$ & -24.61 \\
\hline LHP $2(-Y)$ CC thermistor & -12.26 \\
\hline LHP 2 evaporator & -21.05 \\
\hline LHP 2 vapor line & -31.74 \\
\hline LHP 2 vapor line at condenser & -54.26 \\
\hline LHP 2 lower condenser pass 2 a & -91.73 \\
\hline LHP 2 upper condenser pass 3 a & -91.19 \\
\hline LHP 2 liquid line outlet of condenser & -92.57 \\
\hline LHP 2 inlet to heat exchanger & -72.55 \\
\hline LHP 2 liquid line outlet of heat exchanger & -20.68 \\
\hline LHP 2 liquid return at $\mathrm{CC}$ & -20.75 \\
\hline Radiator Backside, Center & -91.78 \\
\hline Radiator Backside, $+\mathrm{Y} / \mathrm{X}$ Corner & -93.09 \\
\hline DM 1 Housing, $-Z$ & -20.89 \\
\hline DM 2 Housing, - Z & -20.73 \\
\hline DM 3 Housing, $-Z$ & -20.29 \\
\hline DM 4 Housing, $-Z$ & -19.77 \\
\hline DM 5 Housing, $-Z$ & -20.19 \\
\hline DM 6 Housing, $-Z$ & -20.39 \\
\hline DM 7 Housing, $-Z$ & -20.02 \\
\hline DM 8 Housing, $-Z$ & -20.78 \\
\hline DM 9 Housing, $+Z$ & -18.91 \\
\hline DM 10 Housing, $+Z$ & -18.76 \\
\hline DM 11 Housing, $+Z$ & -19.15 \\
\hline DM 12 Housing, $+Z$ & -19.82 \\
\hline DM 13 Housing, $+Z$ & -19.97 \\
\hline DM 14 Housing, $+Z$ & -19.97 \\
\hline DM 15 Housing, $+Z$ & -19.94 \\
\hline DM 16 Housing, $+Z$ & -20.28 \\
\hline DAP Top Facesheet, -Y & -19.64 \\
\hline DAP Top Facesheet, $+Y$ & -20.04 \\
\hline DAP Bottom Facesheet, - Y & -20.17 \\
\hline Mask & -27.2 \\
\hline
\end{tabular}

6 


\section{Thermal Vacuum Cycling Test at Instrument Level}

A T/V cycling test was performed on the BAT instrument from October 28-November 16, 2003.

\section{A. Test Items}

The T/V cycling test items included the following flight units: telescope assembly; Power Converter Box, and Image Processor Electronics primary and redundant units. The test setup for the telescope assembly was the same as that in the BAT T/B test, except that the 5 heater panels around the fringe graded-Z shields/MLI were removed. The end-to-end tilts of the DAP were the same as those in the BAT T/B test.

\section{B. Temperature Cycling Strategy}

The temperature of the Detector Array was cycled by changing the LHP compensation chamber heater controller set point by $1^{\circ} \mathrm{C}$ at a time and to wait until the Block temperatures have begun to flatten out at $0.5^{\circ} \mathrm{C} / \mathrm{hr}$ before making another change. Generally the wait was 20 to 30 minutes long.

During transitions from cold soaks to hot soaks, the sink temperatures for hot $\mathrm{T} / \mathrm{B}$ were used. During transition from hot soaks to cold soaks, the sink temperatures for cold T/B were used.

Because the BAT instrument was powered on and powered off to perform turn-on/turn-off statistics tests at the hot soaks and cold soaks, the following changes were made to the original test procedure to operate the LHPs:

1) At hot soaks, before the Blocks and LHP heater controllers were turned off for a prolonged period of time, the Blocks were powered off first when they reached $22.5^{\circ} \mathrm{C}$, and the set point of the LHP operating mode heater controllers was changed to $24^{\circ} \mathrm{C}$. After verifying that LHPs had shut down, the instrument was powered off. When the instrument was powered on again, the LHP heater controllers were enabled and the set point was changed to $18^{\circ} \mathrm{C}$ as soon as possible, the Block heater controllers were enabled and the set point was changed to $24^{\circ} \mathrm{C}$. The primary survival heaters were enabled, and the redundant survival heaters were disabled. If necessary, the startup heaters were turned on. After verifying that the LHP had started up, the startup heaters were turned off.

2) At cold soaks and intermediate cold plateaus, before the Blocks and LHP heater controllers were turned off for a prolonged period of time, the set point of LHP operating mode heater controller was set to $2^{\circ} \mathrm{C}$ first and then the Blocks were powered off. After verifying that the LHPs had shut down, the redundant survival heaters were enabled and the instrument was powered off. The primary survival heaters were disabled. When the instrument was powered on again, the LHP heater controllers were enabled and the set point was changed to $-11^{\circ} \mathrm{C}$ as soon as possible, the Block heater controllers were enabled and the set point was changed to $-3^{\circ} \mathrm{C}$. When needed the startup heaters were turned on. After verifying that the LHPs had started up, the startup heaters were turned off. When the LHPs settled down, the survival heaters were disabled.

3) At intermediate hot plateaus, before the Blocks and LHP heater controllers were turned off for a prolonged period of time, the Blocks were powered off. When the Blocks reached $12.5^{\circ} \mathrm{C}$, the set point of LHP operating mode heater controllers was changed to $15^{\circ} \mathrm{C}$. After verifying that the LHPs had shut down, the instrument was powered off. When the instrument was powered on again, the LHP heater controllers were enabled and the set point was changed to $8^{\circ} \mathrm{C}$ as soon as possible, and the Block heater controllers were enabled and the set point was changed to $15^{\circ} \mathrm{C}$. The primary survival heaters were enabled and the redundant ones were disabled. When needed the startup heaters were turned on. After verifying that the LHPs had started up, the startup heaters were turned off.

\section{T/V Cycling Test Results}

The temperatures to which the BAT Detector Array was tested are presented in Fig. 9. The LHP compensation chamber temperatures are shown in Fig. 10. Results are summarized in Tables 4 and 5. 


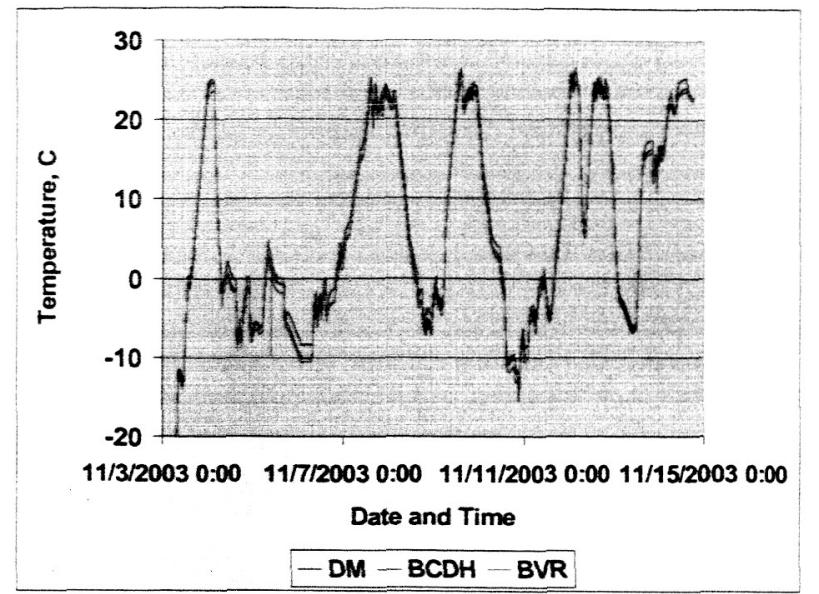

Figure 9. Block DM Temperatures in Instrument Level T/V Cycling Test.

Table 4. Temperatures Achieved in Hot Soaks $\left({ }^{\circ} \mathrm{C}\right)$.

\begin{tabular}{|l|c|c|c|c|c|}
\hline \multirow{2}{*}{ Item } & \multirow{2}{*}{$\begin{array}{c}\text { Hot Soak } \\
\text { Goal }\left({ }^{\circ} \mathrm{C}\right)\end{array}$} & \multicolumn{4}{|c|}{ Hot Soak Achieved $\left({ }^{\circ} \mathrm{C}\right)$} \\
\cline { 3 - 6 } & & $\# 1$ & $\# 2$ & $\# 3$ & $\# 4$ \\
\hline $\begin{array}{l}\text { Blocks } \\
\text { DMs }\end{array}$ & 25 & 23.0 & 23.5 & 23.3 & 23.0 \\
\hline $\begin{array}{l}\text { Blocks } \\
\text { BCDH }\end{array}$ & 25 & 23.5 & 23.5 & 23.3 & 23.0 \\
\hline $\begin{array}{l}\text { Blocks } \\
\text { BVR }\end{array}$ & 25 & 24.3 & 23.6 & 23.3 & 23.0 \\
\hline
\end{tabular}

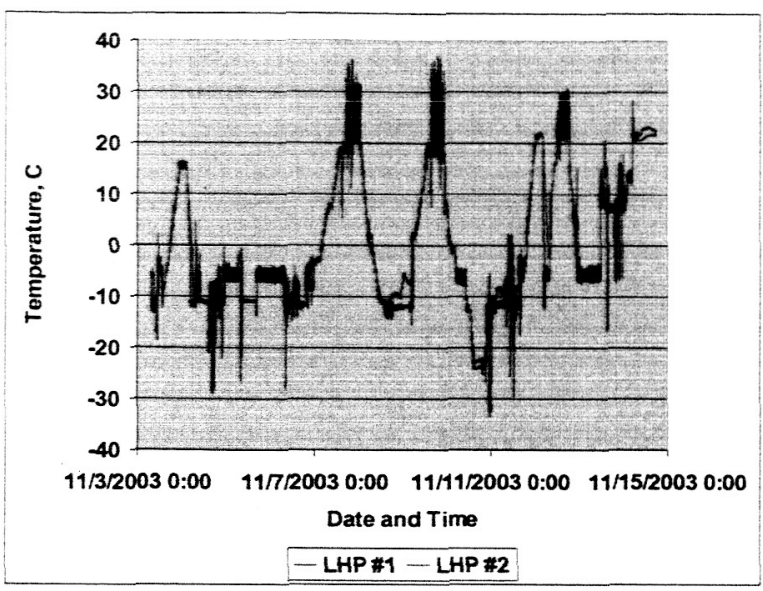

Figure 10. LHP CC Temperatures in Instrument Level T/V Cycling Test.

Table 5. Temperatures Achieved in Cold Soaks $\left({ }^{\circ} \mathrm{C}\right)$.

\begin{tabular}{|l|c|c|c|c|c|}
\hline \multirow{2}{*}{ Item } & \multirow{2}{*}{ Cold Soak } & \multicolumn{4}{|c|}{ Cold Soak Achieved $\left({ }^{\circ} \mathrm{C}\right)$} \\
\cline { 3 - 6 } & & $\# 1$ & $\# 2$ & $\# 3$ & $\# 4$ \\
\hline $\begin{array}{l}\text { Blocks } \\
\text { DMs }\end{array}$ & -3 & -12.5 & -5.5 & -5.5 & -5.3 \\
\hline $\begin{array}{l}\text { Blocks } \\
\text { BCDH }\end{array}$ & -3 & -12.5 & -5.5 & -5.5 & -5.3 \\
\hline $\begin{array}{l}\text { Blocks } \\
\text { BVR }\end{array}$ & -3 & -12.5 & -5.5 & -5.5 & -5.3 \\
\hline
\end{tabular}

\section{Thermal Vacuum Cycling Test at Observatory Level}

\section{A. Test Setup}

An inclinometer was used to measure the tilt angles of the DAP prior to closing the chamber door and pumpdown to ensure that they met the requirement. There was a $1.168 \mathrm{~m}(46 \mathrm{in}) \times 1.575 \mathrm{~m}(62 \mathrm{in})$ cryopanel in front of the BAT radiator to simulate the heat sink for the radiator. The cryopanel requirements are the same as that in the instrument level $\mathrm{T} / \mathrm{V}$ cycling test and are as follows:

$-97^{\circ} \mathrm{C}$ at hot soaks.

$-117^{\circ} \mathrm{C}$ at cold soaks.

When the MSX fixture, which mechanically supported all the cryopanels and heater panels for the observatory, was installed in the vacuum chamber, to prevent interference with the flight hardware it was necessary to make several mechanical changes. As a result of these changes, the BAT radiator cryopanel was higher than the radiator, and the cryopanel did not cover the bottom 6 inches of the radiator. It reduced the radiation coupling between the radiator and cryopanel by about $13 \%$. As a result, the cryopanel temperature requirement was adjusted to $-140^{\circ} \mathrm{C}$ (coldest possible by $\mathrm{GN}_{2}$ ) at both hot soaks and cold soaks.

To prevent contaminants from migrating from the cryopanel to the radiator white paint, the cryopanel was maintained warmer than the radiator throughout the test. The backside of the cryopanel was insulated with an 8layer test MLI. VDA is the thermal coating for the exterior of the outer cover. The gap between the radiator and cryopanel was closed out with an 8-layer test MLI. VDA is the thermal coating for both the exterior and interior of the MLI.

The Instrument Module, which included the BAT telescope assembly, was enclosed in a contamination shroud which was made of 5-mil clear Kapton. The contamination shroud radiated heat to the chamber shroud walls. It was also the heat sink for the mask and LHPs. Because the contamination shroud was a thermal resistance between the Instrument Module and chamber walls, it was slightly warmer than the chamber walls. The chamber shroud was also the heat sink for the spacecraft bus. It was set to $-100^{\circ} \mathrm{C}$ at cold soaks, and $-60^{\circ} \mathrm{C}$ at hot soaks.

8

American Institute of Aeronautics and Astronautics 
During the observatory T/V re-test on the spacecraft bus, one temperature cycle was added to the BAT.

\section{B. Temperature Cycling Strategy}

The temperature of the Detector Array was cycled by changing the LHP compensation chamber heater controller set point by $1^{\circ} \mathrm{C}$ at a time and to wait until the Block temperatures have begun to flatten out at $0.5^{\circ} \mathrm{C} / \mathrm{hr}$ before making another change. Generally the wait was 20 to 30 minutes long.

\section{Test Results}

The temperatures to which the BAT Detector Array was tested are presented in Fig. 11. The LHP compensation chamber temperatures are shown in Fig. 12. Results are summarized in Tables 6 and 7.

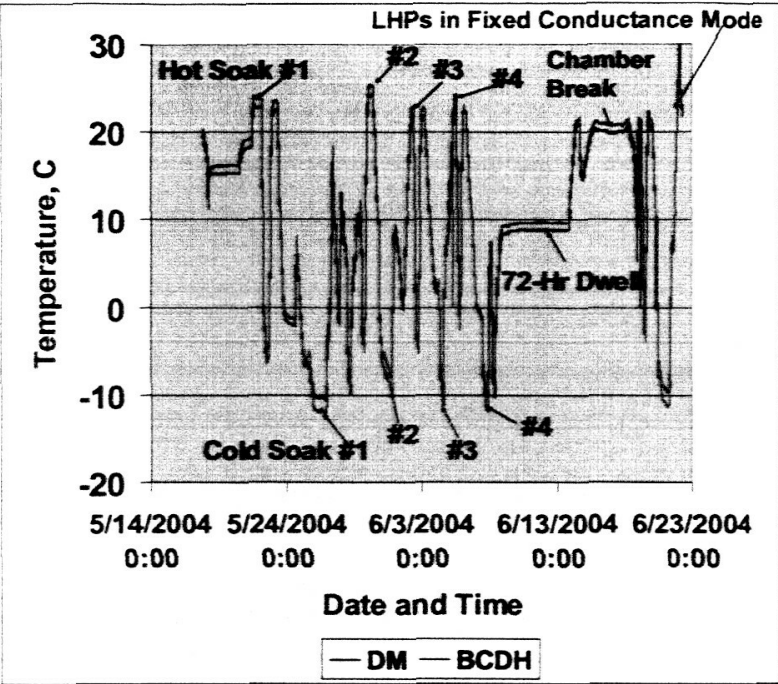

Figure 11. Block DM Temperatures in Observatory Level T/V Cycling Test.

Table 6. Temperatures Achieved in Hot Soaks $\left({ }^{\circ} \mathrm{C}\right)$.

\begin{tabular}{|c|c|c|c|c|c|}
\hline \multirow{2}{*}{ Item } & \multirow{2}{*}{$\begin{array}{c}\text { Hot Soak } \\
\text { Goal }\left({ }^{\circ} \mathrm{C}\right)\end{array}$} & \multicolumn{4}{|c|}{ Hot Soak Achieved $\left({ }^{\circ} \mathrm{C}\right)$} \\
\cline { 3 - 6 } & & $\# 1$ & $\# 2$ & $\# 3$ & $\# 4$ \\
\hline $\begin{array}{l}\text { Blocks } \\
\text { DMs }\end{array}$ & 23 & 22.4 & 23.6 & 21.1 & 21.9 \\
\hline $\begin{array}{l}\text { Blocks } \\
\text { BCDH }\end{array}$ & 23 & 23.4 & 24.7 & 22.3 & 23.6 \\
\hline
\end{tabular}

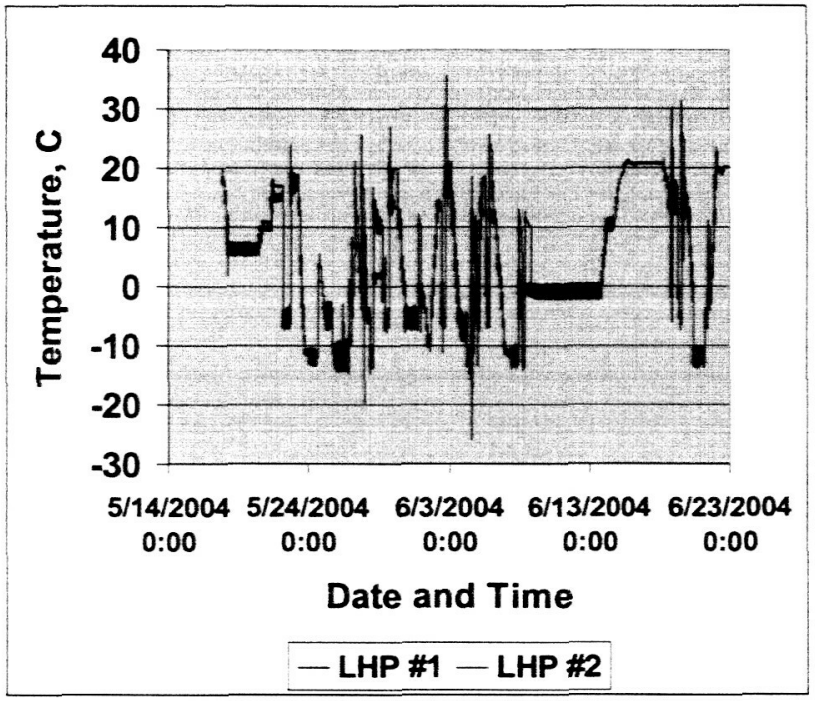

Figure 12. LHP CC Temperatures in Observatory Level T/N Cycling Test.

Table 7. Temperatures Achieved in Cold Soaks $\left({ }^{\circ} \mathrm{C}\right)$.

\begin{tabular}{|c|c|c|c|c|c|}
\hline \multirow{2}{*}{ Item } & \multirow{2}{*}{$\begin{array}{c}\text { Cold Soak } \\
\text { Goal }\left({ }^{\circ} \mathrm{C}\right)\end{array}$} & \multicolumn{4}{|c|}{ Cold Soak Achieved $\left({ }^{\circ} \mathrm{C}\right)$} \\
\cline { 3 - 6 } & & $\# 1$ & $\# 2$ & $\# 3$ & $\# 4$ \\
\hline $\begin{array}{l}\text { Blocks } \\
\text { DMs }\end{array}$ & -3 & -7.5 & -3.0 & -5.5 & -6.1 \\
\hline $\begin{array}{l}\text { Blocks } \\
\text { BCDH }\end{array}$ & -3 & -9.2 & -2.6 & -5.4 & -6.0 \\
\hline
\end{tabular}

\section{LHPs in Fixed Conductance Mode during Return to Ambient Temperature for Backfill}

Warming of observatory to ambient temperature began at 16:30 EDT on June 21, 2004. One component that needed to warm up was the chamber shroud, and it was the heat sink for the spacecraft nickel-hydrogen batteries and BAT LHP compensation chambers. The batteries have a $10^{\circ} \mathrm{C}$ hot yellow limit and $15^{\circ} \mathrm{C}$ red limit. If the battery temperature approached $15^{\circ} \mathrm{C}$, the power to the observatory needed to be turn off immediately. To maintain the instruments powered on during warming up to ambient, the chamber shroud needed to be reasonably cool even if the batteries were not charging. At 21:00 EDT increase of the BAT radiator cryopanel from $-80^{\circ} \mathrm{C}$ to $0^{\circ} \mathrm{C}$ was initiated to make the LHPs go into a "fixed conductance mode". It prevented the temperature of the BAT Blocks from decreasing rapidly when the BAT was powered off and chamber shroud was still cool due to the nickel-hydrogen battery temperature limit.

\section{LHP Startup and Blocks Turn-On Using Flight Operation Procedure}

During the observatory level T/V cycling test, LHP startup and Blocks turn-on was performed twice using the flight operation startup procedure presented at the IECEC in $2003 .^{2}$ 


\section{A. Startup \#1}

On May 28, 2004 night startup for BAT LHP \#1 was successfully completed, and on May 29 morning startup for LHP \#2 was successfully completed. Spacecraft power was on Side A. The sequence of events is as follows:

1) 1200 EDT, May 28: BAT was powered off at end of cold soak \#1. Only redundant survival heaters were enabled.

2) 1430 EDT: LHP's shut down.

3) 1640 EDT: Blocks at $-10^{\circ} \mathrm{C}$ average. IPP was turned on. PCB was turned on. SIM1B began. LHP primary heater controllers were enabled with $0^{\circ} \mathrm{C}$ set point for LHP \#1 and $10^{\circ} \mathrm{C}$ set point for LHP \#2.

4) 1731 EDT: LHP \#1 compensation chamber stabilized at $0^{\circ} \mathrm{C}$ and LHP \#2 compensation chamber stabilized at $10^{\circ} \mathrm{C}$.

5) 1735 EDT: Primary and redundant Block heater controllers were enabled and set point set to $8^{\circ} \mathrm{C}$. LHP \#1 startup heater was turned on.

6) 1925 EDT: LHP \#1 started. Turn-on of Blocks began.

7) 0015 EDT, May 29: 4 Blocks were turned on. Redundant Block heater controllers were disabled.

8) 0230 EDT: A total of 8 Blocks were turned on.

9) 0415 EDT: A total of 12 Blocks were turned on.

10) 0700 EDT: Block temperatures stabilized $\left(<0.5^{\circ} \mathrm{C} / \mathrm{hr}\right)$. LHP \#1 startup heater was turned off. LHP \#2 heater controller set point was changed to $0^{\circ} \mathrm{C}$.

11) 0829 EDT: LHP \#2 startup heater was turned on.

12) 0841 EDT: LHP \#2 started.

13) 0922 EDT: LHP \#2 temperatures began to stabilize. Then startup heater was turned off. Turn-on of last 4 Blocks began.

14) 1025 EDT: All 16 Blocks were turned on. SIM 1B was completed.

\section{B. Startup \#2}

On June 8, 2004 afternoon, startup for LHP \#1 was successfully completed, and before mid-night, startup for LHP \#2 was successfully completed. Spacecraft power was on Side B. The sequence of events is as follows:

1) 0520 EDT, June 8: BAT was powered off after observatory abbreviated integrated system test (AIST) and orbit in the life (OITL) test at cold soak \#4. Only redundant survival heaters were enabled on BAT.

2) 0810 EDT: LHP's shut down.

3) 0931 EDT: Blocks at $-10^{\circ} \mathrm{C}$ average. IPR was turned on. PCB was turned on. SIM1B BAT activation began.

4) 0952 EDT: LHP redundant heater controllers were enabled with $0^{\circ} \mathrm{C}$ set point for LHP \#1 and $10^{\circ} \mathrm{C}$ set point for LHP $\$ 2$.

5) 1015 EDT: LHP \#1 compensation chamber stabilized at $0^{\circ} \mathrm{C}$ and LHP \#2 compensation chamber stabilized at $10^{\circ} \mathrm{C}$.

6) 1029 EDT: Primary and redundant Block heater controllers were enabled and set point set to $8^{\circ} \mathrm{C}$. LHP \#1 redundant startup heater was turned on.

7) 1229 EDT: LHP \#1 started. Turn-on of Blocks began.

8) 1536 EDT: A total of 4 Blocks were turned on. Redundant Block heater controllers were disabled.

9) 1911 EDT: A total of 12 Blocks were turned on.

10) 1945 EDT: Block temperatures stabilized $\left(<0.5^{\circ} \mathrm{C} / \mathrm{hr}\right)$. LHP \#1 redundant startup heater was turned off. LHP \#2 redundant heater controller set point was changed to $0^{\circ} \mathrm{C}$. LHP \#2 redundant startup heater was turned on.

11) 1947 EDT: LHP \#2 started.

12) 2023 EDT: LHP \#2 temperatures began to stabilize. Then startup heater was turned off.

13) 2046 EDT: All 16 Blocks were turned on.

14) 2306 EDT: Both LHP's were stable. Blocks began to level off at $8^{\circ} \mathrm{C}$.

\section{Conclusion}

The T/B test results have validated that the BAT telescope assembly thermal design, including the LHP thermal system, satisfies the thermal requirements of the instrument in the flight thermal environments. From the results of the hot operating T/B test and cold operating T/B test, when the Detector Array is powered on and both LHPs are running, the average temperature of the DMs is about $8.5^{\circ} \mathrm{C}$ warmer than the set point of the LHP compensation chamber heater controllers. It is close to the $10^{\circ} \mathrm{C}$ gradient predicted in designing the LHP thermal system. The T/B test was the first 
time that the BAT had the LHPs and radiator integrated to it and tested in vacuum. It showed that the two LHPs worked in harmony thermally to share the heat transport from the DAP to the radiator.

During the observatory level T/V cycling test, LHP startup and Blocks turn-on was successfully completed twice using the flight operation startup procedure. In flight, using the flight operation startup procedure, LHP startup and Detector Array Blocks turn-on should be successful. To satisfy a total of 12 thermal vacuum cycles before launch and to meet schedule, T/V cycling test on the BAT, including the Detector Array, was performed at both the instrument level and observatory level. The temperature of the Detector Array was successfully cycled by changing the LHP compensation chamber heater controller set point by $1^{\circ} \mathrm{C}$ at a time and to wait until the Block temperatures have begun to flatten out at $0.5^{\circ} \mathrm{C} / \mathrm{hr}$ before making another change. Generally the wait was 20 to 30 minutes long and it prevented the LHPs from shutting down or having cold shocks.

\section{References}

${ }^{1}$ Choi, M. K., "Thermal Design to Meet Stringent Temperature Gradient/Stability Requirements of Swift BAT Detectors," Paper No. AIAA-2000-2905, IECEC 2000, Las Vegas, NV, July 24-28, 2000.

${ }^{2}$ Choi, M. K., "Swift BAT Loop Heat Pipe Thermal System Characteristics and Ground/Flight Operation Procedure," Paper No. AIAA-2003-6077, ${ }^{\text {st }}$ International Energy Conversion Engineering Conference, Portsmouth, VA, Aug. 13-16, 2003. 